\title{
LABORATORY BASED OF SURVEILLANCE FOR LEPTOSPIROSIS IN LVIV OBLAST, UKRAINE
}

\section{Liliia Vasiunets, Oksana Semenyshyn, Oksana Velychko, Lesja Hatsiy, Iryna Kulish}

\author{
EDP laboratory, State Institution Lviv Oblast Laboratory Center of the Ministry of Health of Ukraine, Lviv, Lviv, Ukraine
}

Objective

To estimate effectiveness of PCR method for epidemiology surveillance for leptospirosis in Lviv Oblast and compare it with microscopic agglutination test (MAT).

Introduction

Leptospirosis is one of the most important zoonotic diseases based on the severity of the clinical course, frequency of fatal outcome and long-term clinical consequences. In Ukraine, leptospirosis is one of the most widespread natural-focal infectious diseases. Based on data of the Public Health Center of the Ministry of Health of Ukraine in 2017, the incidence rate was 0.77 per 100,000 population (330 cases), mortality rate was 0,08 per 100000 population (case fatality rate was 10,9\%). In Lviv Oblast, the disease was registered as sporadic cases that were not related to each other (in 2017, the incidence rate was 0.72 per 100,000 population [1]. Laboratory testing of samples collected from patients and environmental objects that may be the source of the pathogen is an integral part of the epidemiological surveillance of leptospirosis. Modern laboratory diagnostics of leptospirosis is based on microbiological, immunological and molecular-biological methods used in various combinations [2,3]. Molecular genetic diagnostic methods that allow detection of the Leptospira spp. RNA/DNA are the most promising for diagnosis of leptospirosis in the early stages of the disease. Investigation of environmental objects allows timely detection of the pathogen in natural foci and conducting a set of anti-epidemic necessary measures.

\section{Methods}

We used the following PCR kits "Leptospira pathogenic-Real time (FR001) Genecam Biotechnology AG" and "LPS PCR kit variant FRT-50F "Amplisens" for leptospira DNA detection. "Ultra Clean Blood Spin DNA isolation kit MO BIO Laboratories, Inc." and a set of reagents from the clinical materials "RIBO-prep" for the isolation of RNA / DNA loci of Leptospira spp. were used.

In parallel, 37 human and 27 rodent serum samples were studied using MAT. PCR and MAT positive gray rats samples were additionally studied using the bacteriology method (adrenal cortex seeded on the liquid media). Epidemiological investigation (namely, patient interviewing, investigation of places where the infection was acquired, exploring the living conditions) and outbreak investigation report writing were conducted for all recorded cases (41).

\section{Results}

Results of the human samples investigation. During 2016-2017 and 7 months of 2018, 41 cases of leptospirosis were registered in Lviv Oblast. All these cases were confirmed with laboratory methods, including PCR; DNA of Leptospira spp. was detected in 15 patients $(36,6 \%)$, and MAT was positive in 26 cases $(63,4 \%)$. In 8 patients $(19,5 \%)$ both PCR and MAT testing gave positive results. Over the past three years, 5 fatal cases of leptospirosis (12.1\%) have been registered, including two patients who died during the first week of the disease. For those two patients, the diagnosis was confirmed by PCR and MAT (leptospira lysis in MAT was noticed in the titre of 1:100-1:200); for other two patients, the diagnosis was confirmed using MAT only (1:800); and in the last patient from this group, leptospira lysis was noticed in low titres in MAT.

Results of epidemiological investigation revealed that the most patients were infected through contact way of transmission (78.1\%), including contact with objects and food contaminated with rodent excrement, and water-borne transmission (19.5\%) during bathing, fishing, hunting, field work; in other $2.4 \%$ of cases the way of transmission was not identified. Epidemiological history showed that the main source of infection for humans in natural and urban foci were grey rats and rodents that could adapt to transforming ecosystems conditions.

SDS Annual Conference Proceedings 2019. This is an Open Access article distributed under the terms of the Creative Commons AttributionNoncommercial 4.0 Unported License (http://creativecommons.org/licenses/by-nc/3.0/), permitting all non-commercial use, distribution, and reproduction in any medium, provided the original work is properly cited. 
Results of animal samples investigation. Among 27 samples of gray rats, caught in places where patients probably got infected, in 11 samples (40.7\%) a specific 16S rRNA of Leptospira spp. was detected and also MAT was positive; 1 samples (3,7\%) from this group was seropositive in MAT only.

L. icterohaemorrhagiae live culture was isolated from 3 samples of grey rats that were positive in PCR and MAT.

Results of environmental samples investigation showed the following: among 89 of water samples collected from recreation areas (lakes), 4 samples (4.5\%) were positive (16S rRNA of Leptospira spp.). PCR of 8 samples of drinking water collected from leptospirosis foci gave negative results.

\section{Conclusions}

In Lviv Oblast, Ukraine, the potential of laboratory diagnostics of leptospirosis has increased due to introduction of PCR method in diagnostic algorithm. Results of clinical materials investigations revealed that with PCR it is became possible to confirm the diagnosis within the first several days from the onset of the disease (in 15 patients). Diagnosis was confirmed using MAT in 26 patients starting from the second week of the disease. At the same time, MAT is crucial, since it enables to identify the etiological structure of the disease and monitor the dynamics of the immune response.

Investigation of animal and environmental samples with MAT and PCR methods allowed to establish causal relationships of patients with possible sources of infection. PCR method allowed to conduct epidemiological surveillance for leptospirosis at a new level, as the time for receiving results compare to the classical methods as well as biological risks during work with biomaterials have decreased.

Currently, the combination of PCR and MAT methods for laboratory research in the surveillance of leptospirosis is optimal.

Understanding environmental and epidemiological determinants allows for the identification of appropriate public health approaches to improve the situation with leptospirosis, such as reducing populations of pathogen reservoirs (rats) by conducting deratization measures, vaccinations of dogs and livestock, and regulatory compliance.

\section{Acknowledgement}

Authors would like to express their gratitude to Defense Threat Reduction Agency and Ukraine Biological Threat Reduction Program for the providing diagnostic PCR kits.

\section{References}

1. About the epidemiological situation with leptospirosis in Ukraine in 2017 and measures to prevent it / Information letter of PHC of the Ministry of Health of Ukraine, 20.07.2018 \# 2651. - Kyiv. - 2018. - 26 p.

2. Budihal SV, Perwez K. 2014. Leptospirosis diagnosis: competancy of various laboratory tests. J Clin Diagn Res. 8(1), 199-202.

3. World Health Organization. (2003). Human leptospirosis: guidance for diagnosis, surveillance and control. World Health Organization. 